\title{
PEMBERDAYAAN MASYARAKAT MELALUI DIVERSIFIKASI PRODUK ROSELLA DI KAMPUNG PADUAN RAJAWALI, TULANG BAWANG
}

\author{
Elhamida Rezkia Amien ${ }^{1 *}$, Muhammad Haviz ${ }^{2}$, Titin Yulianti ${ }^{3}$, Diding Suhandy ${ }^{1}$, Mareli \\ Telaumbanua ${ }^{1}$ \\ ${ }^{1}$ Jurusan Teknik Pertanan, Fakultas Pertanian, Universitas Lampung, Bandar Lampung \\ ${ }^{2} J u r u s a n$ Teknik Kimia, Fakultas Teknik, Universitas Lampung, Bandar Lampung \\ ${ }^{3}$ Jurusan Teknik Elektro, Fakultas Pertanian, Universitas Lampung, Bandar Lampung \\ Jl. Prof. Sumantri Brojonegoro No.1 Bandar Lampung 35145 \\ *Penulis Korespodensi : elhamida.rezkiaamien90@fp.unila.ac.id
}

\begin{abstract}
Abstrak
Desa Paduan Rajawali merupakan salah satu sentra penghasil Rosella di Kabupaten Tulang Bawang. Produk yang dihasilkan hanya ditangani dengan cara yang sederhana. Akibatnya produk mengalami kendala untuk dapat dipasarkan secara global. Selain itu, pemasaran produk Desa hanya sebatas pameran produk yang di adakan pada tingkat lokal dan provinsi sehingga kegiatan yang dilakukan oleh Kelompok Wanita Kreatif Rosella ini tidak signifikan meningkatkan pendapatan desa. Pengabdian ini bertujuan untuk meningkatkan produktifitas produk olahan Rosella melalui penambahan varian produk Rosella dan pengemasan produk. Metode yang digunakan untuk mendukung kegiatan ini ialah dengan memberikan edukasi dan pendampingan tentang pengolahan produk-produk hasil pertanian khususnya Rosella. Materi kegiatan pengabdian sangat sesuai dengan kebutuhan mitra dan pelaksanaan kegiatan secara berkelanjutan yang ditunjukkan dengan $80 \%$ peserta memberikan penilaian sangat setuju (SS) dan $60 \%$ peserta menyatakan bahwa peralatan yang digunakan sesuai kebutuhan dan mudah untuk digunakan. Mitra juga menyambut dengan baik disain logo yang diberikan, saran pengemasan, tambahan produk, serta pemasaran online yang telah dibuatkan. Mitra sangat antusias terhadap kegiatan ini dan berharap dilakukan pendampingan serupa
\end{abstract}

Kata kunci: diversifikasi, produk Rosella, Rosella

\section{Pendahuluan}

Desa Paduan Rajawali terletak di Kecamatan Meraksa Aji yang berjarak sekitar $63 \mathrm{Km}$ dari ibu kota Kabupaten Tulang Bawang. Mayoritas penduduk desa berprofesi sebagai petani karet, sawit, singkong, dan sebagian kecil bekerja di pabrik sekitar. Desa Paduan Rajawali memiliki luasan $846 \mathrm{Ha}$. Sebagian kecil tutupan lahan adalah pemukiman dan sisanya adalah areal perkebunan dan persawahan. Potensi alam yang dimiliki desa, sangat mendukung kegiatan pertanian.

Bunga Rosella menjadi salah satu daya tarik desa. Bahkan bunga Rosella pun menjadi icon dari Desa Paduan Rajawali karena desa ini dikenal sebagai penghasil bunga Rosella yang dikembangkan di sejumlah lahan kosong yang ada di sekitar Balai Desa dan beberapa pekarangan warga. Setiap tahunnya, penanaman Rosella rutin dilakukan. Penanaman umumnya dilakukan pada bulan Februari dan pada pertengahan tahun bunga Rosella dapat dipanen. Satu tanaman Rosella dapat menghasilkan 200-1000 gram bunga basah (BPTP Sumsel, 2019).

Bunga Rosella memiliki banyak manfaat. Dari berbagai penelitian yang telah dilakukan yang menyebutkan bahwa Rosella mengandung antosianin yang dapat menangkal radikal bebas (Pangaribuan. 2016). Selain itu, Rosella yang telah dikeringkan dapat diolah menjadi teh merah yang berkhasiat untuk mengobati berbagai penyakit, salah satunya hipertensi (Mun'im, dkk. 2008). Potensi yang dimiliki Rosella menjadikan bunga ini digemari untuk dijadikan obat tradisional dan produk yang dapat dikonsumsi sehari-hari.

Untuk memenuhi animo pasar yang tinggi, maka diharapkan Desa Paduan Rajawali melalui Kelompok Wanita Kreatif Rosella dapat memanfaatkan peluang yang ada dengan 
menghasilkan produk yang dapat bersaing luas di luar wilayah Tulang Bawang. Penggunaan logo dan pengemasan yang menarik menjadi penting untuk dilakukan. Logo merupakan identitas sebuah produk yang dapat menjadi daya tarik tersendiri dari sebuah produk (Oscario, 2013).

Melalui kegiatan diversifikasi produk Rosella diharapkan mampu meningkatkan produktifitas produk olahan Rosella melalui penambahan varian produk Rosella dan pengemasan produk.

\section{Bahan dan Metode}

\section{A. Bahan dan Alat}

Bahan yang digunakan pada kegiatan ini adalah bunga Rosella, standing pouch, botol almond, dan botol selai. Alat yang digunakan adalah kompor, panci, wajan, blender, sealer, dan timbangan digital.

\section{B. Metode}

Metode yang digunakan pada kegiatan ini ialah dengan memberikan edukasi dan pendampingan tentang pengolahan produk-produk hasil pertanian khususnya Rosella. Tahapan kegiatan program pengabdian kepada masyarakat meliputi : perumusan masalah dengan mitra, perencanaan solusi dari permasalahan yang ada yaitu dengan melakukan diversifikasi produk, penyuluhan dan pelatihan pembuatan produk, monitoring, dan terakhir adalah evaluasi kegiatan.

Pelaksanaan kegiatan ini dilaksanakan dengan tahapan sebagai berikut:

\section{Perencanaan logo dan kemasan}

Perencanaan sebuah logo merupakan hal penting yang perlu dilakukan karena logo menyampaikan cita-cita dan filosofi sebuah produk. Selain itu, logo dan kemasan yang sesuai juga menunjukkan keseriusan sebuah usaha untuk memasarkan produknya. Desain logo ini akan dilakukan dari hasil diskusi dengan Kolompok Wanita Kreatif Rosella.

\section{Sosialisasi varian produk}

Sosialisasi varian produk akan disampaikan pada pertemuan awal yang menjelaskan rencana produk yang akan dijalankan. Sosialisasi ini akan diikuti oleh seluruh warga yang tergabung kedalam Kelompok Wanita Kreatif Rosella, warga yang berminat, dan aparatur desa serta kecamatan untuk mendampingi. Harapannya melalui sosialisasi ini kelompok penggerak dapat memotifasi anggota kelompoknya untuk berperan aktif menyukseskan usaha yang akan mereka kembangkan.

3. Pembuatan produk

Produk yang akan dihasilkan antara lain : teh Rosella, teh celup, sirup, dan selai Rosella. Tahapan kegiatan ditampilkan pada Gambar 1.

4. Pendampingan

Setelah kelompok mampu membuat produk secara mandiri, dilakukan pendampingan dalam pelaksanaan rencana kegiatan. Kelompok dimonitoring baik secara langsung (datang ke lokasi) maupun tidak langsung (melalui media whatsapp dan media lain).

\section{Pemasaran online}

Hilir dari sebuah usaha adalah pemasaran produk. Untuk menunjang keberlangsungan sebuah usaha, kegiatan pemasaran amatlah penting. Dalam program ini, kelompok dibuatkan akun sosial media sepetri Instagram yang di dalamnya akan dipaparkan produk-produk yang dihasilkan, manfaat produk serta cara penggunaan produk

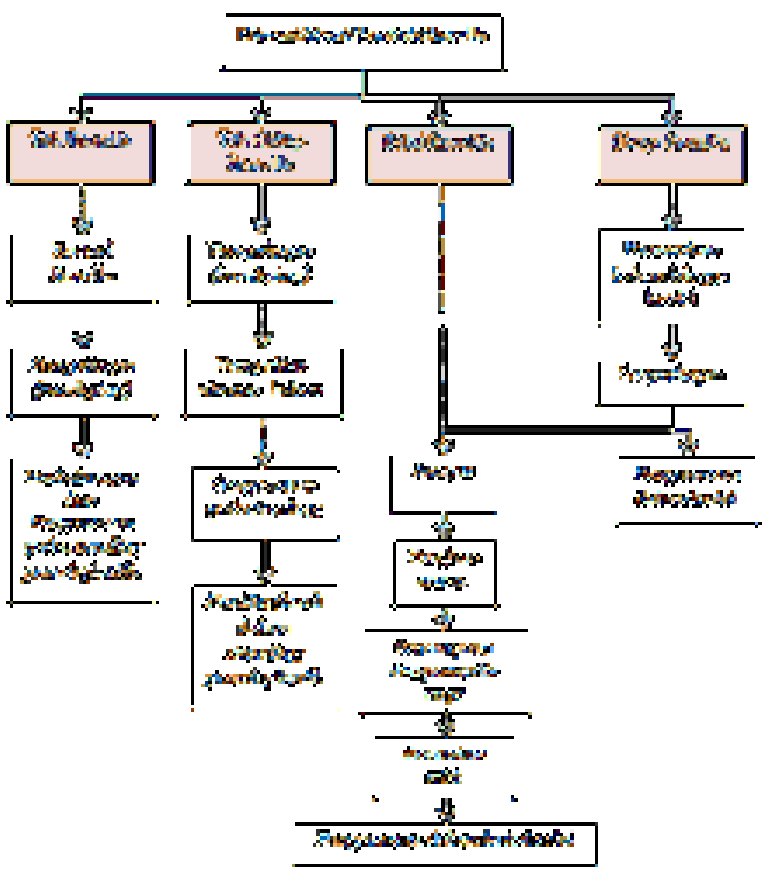

Gambar 1. Tahapan Pembuatan Produk

\section{Hasil dan Pembahasan}

\section{A. Pembuatan Logo}

Logo produk didesain semenarik mungkin yang menggambarkan produk yang dimiliki. Bunga Rosella ditampilkan menggantikan huruf $\mathrm{O}$ pada kata ROSELLA untuk memberikan cirikhas dari 
produk yang dihasilkan. Logo Produk ditampilkan pada Gambar 2.

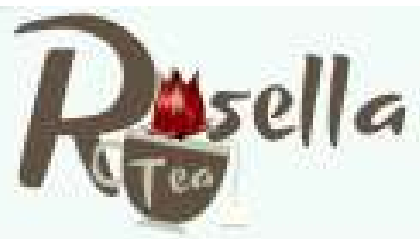

Gambar 2. Logo Produk

Selain penggunaan logo, desain label pun perlu diperhatikan untuk menunjang tampilan produk. Gambar 3 a merupakan tampilan untuk teh Rosella dalam bentuk original. Gambar 3 b merupakan tampilan label untuk teh celup, Gambar 3 c dan 3 d merupakan tampilan selai dan sirup Rosella. Masing-masing label terdiri dari nama produk, logo, komposisi, berat, tanggal kadaluarsa, keterangan produksi serta nomor perizinan.

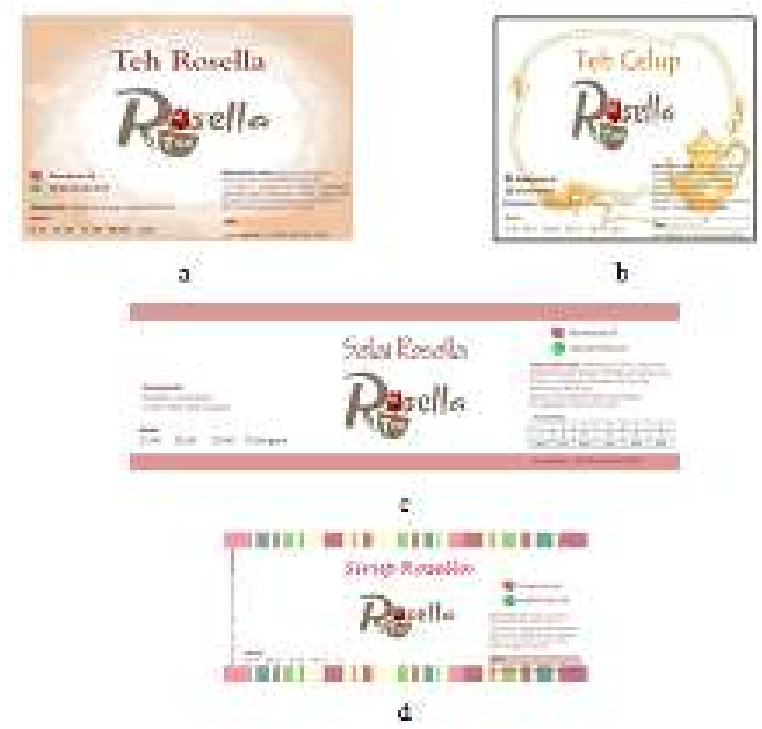

Gambar 3. Label (a) Teh Rosella, (b) Teh Celup, (c) Selai, dan (d) Sirup

\section{B. PembuatanVarian Produk}

Produk olahan Rosella dihasilkan dari Bunga Rosella yang telah berwarna merah tua. Bunga dipanen dengan pemetikan manual kemudian dicuci bersih untuk menghilangkan debu dan serangga. Selanjutnya dilakukan sortasi untuk memisahkan bunga yang dijadikan teh dan bunga yang langsung diolah.

1. Pembuatan teh Rosella

Setelah proses sortasi, bunga Rosella dikeringkan dibawah sinar matahari untuk mengurangi kadar air.
Hal ini dilakukan untuk menjaga mutu bunga yang akan dijual dan agar lebih tahan lama. Waktu yang dibutuhkan untuk proses ini tergantung radiasi matahari yang terjadi. Jika bunga telah kering (mencapai kadar air $\pm 15 \%$ ) yang ditandai dengan berkurangnya ketebalan Rosella dan perubahan warna menjadi merah kecoklatan, maka pengeringan dihentikan. Hasil pengeringan disimpan dalam plastik yang tertutup rapat yang selanjutnya akan dikemas kedalam kemasan kecil. Teh Rosella ini berbentuk kolopak bunga asli tanpa proses penghancuran.

\section{Pembuatan teh celup}

Bahan yang digunakan pada pembuatan teh celup adalah teh Rosella. Teh Rosella yang telah kering dihaluskan dengan menggunakan blender. Selanjutnya dimasukkan ke tea bag sebanyak $3 / 4$ sendok makan lalu dipress. Teh celup merupakan produk baru yang merupakan ide dari ketua kelompok untuk menambah varian produk Rosella yang dihasilkan.

\section{Pembuatan sirup}

Bahan utama yang digunakan untuk pembuatan sirup Rosella adalah bunga Rosella segar. Bahan tambahan yang digunakan antara lain gula pasir, gula batu, garam, daun pandan, dan air. Semua bahan dimasak hingga mengental. Setelah mengental, sirup didinginkan, disaring, dan siap untuk dikemas.

4. Pembuatan selai

Hasil penyaringan sirup digunakan sebagai bahan tambahan untuk pembuatan selai dengan dihaluskan bersama dengan Rosella segar. Bahan lain yang digunakan untuk pembuatan selai Rosella adalah gula pasir, gula batu, dan garam. Selai Rosella yang dihasilkan oleh kelompok ini tidak mengguanakan bahan pengawet dan pewarna buatan sehingga sangat aman untuk dikonsumsi.

\section{Pengemasan dan Labeling}

Pengemasan disesuaikan dengan produk yang ada. Pengemasan yang baik dan menarik merupakan sarana komunikasi antara produsen dan konsumen tentang produk di dalam kemasan (Novita dan Rahmawati, 2020). Beberapa unsur yang perlu diperhatikan dalam pengemasan adalah nama produk/jenis produk, tanggal kadaluarsa, berat produk, komposisi, serta nomor perizinan. Untuk tanggal kadaluarsa ditentukan berdasarkan umur simpan produk. Teh Rosella dan teh celup memiliki 
umur simpan \pm 1 tahun. Selai dan sirup memiliki umur simpan \pm 5 bulan jika disimpan dalam kulkas.

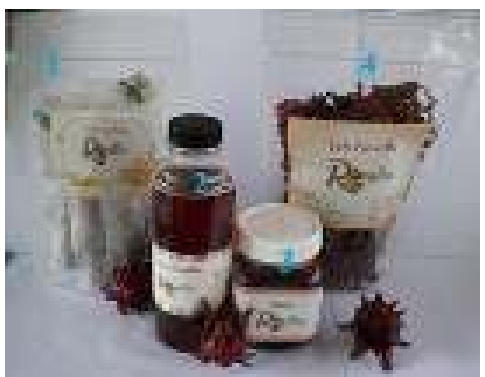

Gambar 4. Kemasan dan Labeling Produk

Gambar 4 merupakan tampilan dari produk yang telah dikemas. Tampilan teh celup yang ditunjukkan oleh nomor 1 pada Gambar 4 merupakan produk terbaru yang dihasilkan. teh celup dikemas dalan standing pouch dengan ukuran $10 \times 17 \mathrm{~cm}$ yang berisi 10 kantong teh. Nomor 2 pada Gambar 4 merupakan sirup Rosella yang dikemas di dalam botol plastik dengan volume $200 \mathrm{ml}$. Sebelumnya sirup Rosella dikemas pada botol sirup berbahan kaca. Selai Rosella dikemas dalam botol plastik khusus yang ditunjukkan oleh nomor 3. Satu botol berisikan 200 gr selai Rosella. Produk terakhir yaitu teh Rosella dikemas dalam standing pouch berukuran 16×24 cm dengan massa 50 gr. Sebelumnya teh Rosella ini dikemas dalam plastik mika dengan bobot 100 gr yang dipress untuk packingnya. Melalui penggunan kemasan yang lebih menarik diharapkan dapat meningkatkan kepercayaan diri kelompok tani bahwa produk yang dihasilkan dapat bersaing dengan produk lain.

\section{Pemasaran Online}

Pemasaran online saat ini sedang berkembang pesat, terbukti dari menjamurnya toko-toko online. Untuk menunjang pemasaran online, maka kolompok tani perlu memiliki akun sosial media yang sedang populer yaitu Instagram. Instagram merupakan aplikasi untuk mengunggah gambar yang disertai dengan caption dan hastag. Pengambilan gambar produk yang menarik merupakan kunci dari pemasaran secara online. Beberapa perwakilan dari kelompok tani diberikan praktik langsung untuk photoshoot produk dengan memperhatikan background, ketajaman gambar, penentuan angle, dan pencahayaan.
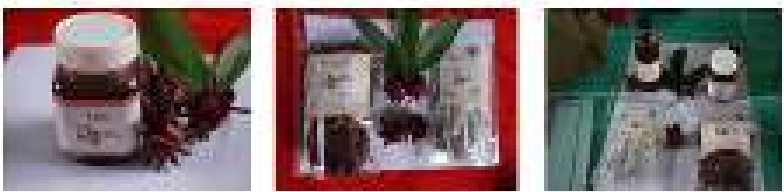

Gambar 5. Pelatihan Pengambilan Foto dan Penggunaan Background Produk

Profil Instagram yang dimiliki kelompok ditampilkan pada Gambar 6. Instagram ini bersifat bisnis sehingga memiliki tampilan yang berbeda dengan instagram pribadi. Nama akun yang digunakan adalah roselatea.id. Nama akun pun telah ditampilkan pada seluruh label produk yang disertakan juga dengan nomor whatsapp.

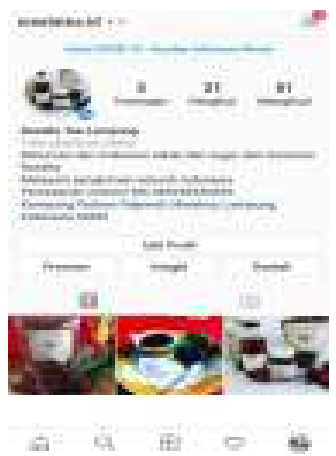

Gambar 6. Tampilan Instagram

\section{E. Hasil Evaluasi}

Evaluasi kegiatan dilakukan dengan memberikan kuisioner yang yang berisi beberapa pertanyaan tentang kegiatan pengabdian yang dilakukan, produk yang digunakan, dan saran. Skala penilaian yang digunakan adalah skala Likert dengan 4 titik respon yaitu sangat setuju (SS),setuju (S), tidak setuju (TS), dan sangat tidak setuju (STS). Kuisioner diikuti oleh 10 peserta yang terdiri dari anggota kelompok, perwakilan perangkat desa, dan kecamatan.

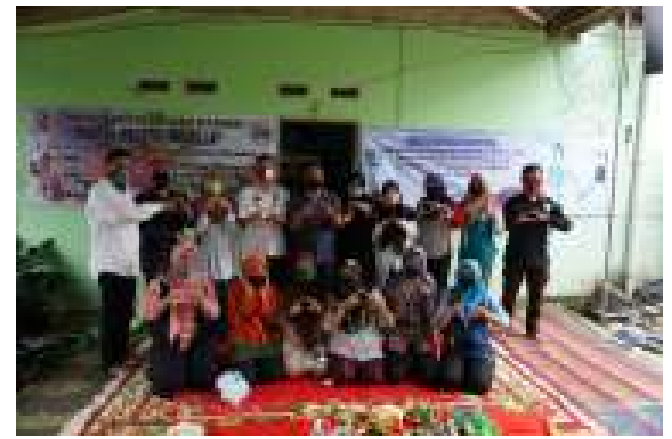

Gambar 7. Peserta Kegiatan 
Pada Tabel 1 terlihat bahwa materi kegiatan pengabdian sangat sesuai dengan kebutuhan mitra dan pelaksanaan kegiatan secara berkelanjutan yang ditunjukkan dengan $80 \%$ peserta memberikan penilaian sangat setuju (SS). Pada evaluasi terhadap pelaksanaan kegiatan, manfaat langsung yang diperoleh, dan kepuasan terhadap kegiatan, diperoleh $50 \%$ peserta memberi penilaian sangat setuju (SS).

Tabel 1. Kuisioner Tentang Pelaksanaan Kegiatan

\begin{tabular}{|c|c|c|c|c|c|c|}
\hline \multirow[b]{2}{*}{ No. } & \multirow[b]{2}{*}{ Pertanyaan } & \multicolumn{4}{|c|}{ Skala Penilaian } & \multirow[b]{2}{*}{ Total } \\
\hline & & $\begin{array}{l}\mathbf{S} \\
\mathrm{S}\end{array}$ & $\mathbf{S}$ & $\begin{array}{l}\mathrm{T} \\
\mathrm{S}\end{array}$ & STS & \\
\hline 1. & $\begin{array}{l}\text { Materi kegiatan sesuai } \\
\text { dengan kebutuhan } \\
\text { mitra/peserta }\end{array}$ & 8 & 2 & & & 10 \\
\hline 2. & $\begin{array}{l}\text { Kegiatan yang } \\
\text { dilaksanakan sesuai } \\
\text { dengan harapan } \\
\text { mitra/peserta }\end{array}$ & 5 & 5 & & & 10 \\
\hline 3. & $\begin{array}{l}\text { Mitra/peserta } \\
\text { mendapatkan manfaat } \\
\text { langsung dari kegiatan } \\
\text { yang dilaksanakan }\end{array}$ & 5 & 5 & & & 10 \\
\hline 4. & $\begin{array}{l}\text { Mitra puas terhadap } \\
\text { kegiatan yang } \\
\text { dilaksanakan }\end{array}$ & 5 & 5 & & & 10 \\
\hline 5. & $\begin{array}{l}\text { Kegiatan dilaksanakan } \\
\text { secara berkelanjutan }\end{array}$ & 8 & 2 & & & 10 \\
\hline
\end{tabular}

Tabel 2. Kuisioner Tentang Produk yang Digunakan

\begin{tabular}{lllllll}
\hline & & \multicolumn{4}{c}{ Skala Penilaian } & \multirow{2}{*}{ Potal } \\
No. & \multicolumn{1}{c}{ Pertanyaan } & S & S & T & STS & Total \\
\hline 1. & $\begin{array}{l}\text { Peralatan yang } \\
\text { digunakan sesuai } \\
\text { dengan kebutuhan }\end{array}$ & 6 & 4 & & $\mathbf{1 0}$ \\
mitra/peserta & & & & & \\
2. & $\begin{array}{l}\text { Kemasan yang } \\
\text { disarankan menarik } \\
\text { Peralatan produksi } \\
\text { mudah digunakan }\end{array}$ & 6 & 7 & & $\mathbf{1 0}$ \\
3. & 6 & 4 & $\mathbf{1 0}$ \\
\hline
\end{tabular}

Tabel 2 merupakan penilaian tentang produk yang digunakan. Dari 10 peserta, $60 \%$ peserta menyatakan bahwa peralatan yang digunakan sesuai kebutuhan dan mudah untuk digunakan. Pada evaluasi terhadap kemasan yang disarankan $70 \%$ peserta menilai kemasan yang digunakan menarik. Selain mengisi kuisioner, beberapa peserta memberikan saran agar kegiatan pengabdian ini dapat dilakukan berkesinambungan dan dilakukan pendampingan kepada mitra.

\section{Kesimpulan}

Kegiatan pengabdian masyarakat telah dilaksanakan dengan baik dan lancar meskipun dalam masa pandemi karena Covid-19. Materi kegiatan sangat sesuai dengan kebutuhan mitra dan pelaksanaan kegiatan secara berkelanjutan yang ditunjukkan dengan $80 \%$ peserta memberikan penilaian sangat setuju (SS) dan 60\% peserta menyatakan bahwa peralatan yang digunakan sesuai kebutuhan dan mudah untuk digunakan. Mitra juga menyambut dengan baik disain logo yang diberikan, saran pengemasan, tambahan produk, serta pemasaran online yang telah dibuatkan. Mitra sangat antusias terhadap kegiatan ini dan berharap dilakukan pendampingan serupa

\section{Ucapan Terima Kasih}

Ucapan terimakasih disampaikan kepada Lembaga Penelitian dan Pengabdian kepada Masyarakat (LPPM) Universitas Lampung yang telah membiayai kegiatan pebangdian skema pemula melalui dana BLU berdasarkan Surat Perjanjian Kontrak Nomor: 1678/UN26.21/PN/2020 Tanggal 24 Maret 2020.

\section{Daftar Pustaka}

[BPTP Sumsel] BPTP Sumatera Selatan. 2019. Budidaya Tanaman Rosella (Hibiscus sabdariffa L.) Roselindo 2. (diakses pada 22/02/2020). http://sumsel.litbang.pertanian.go.id/web/beritabudidaya-tanaman-rosella-hibiscus-sabdariffa-lroselindo-2.html.

Mun'im A, Hanani E, Mandasari A. 2008. Pembuatan Teh Herbal Campuran Rosella Bunga Rosella (Hibiscus sabdariffa L) dan Herba Seledri (Apium graveolens). Majalah Ilmu Kefarmasian V (1): 47-54.

Novita D D dan Rahmawati W. 2020. Pemberdayaan Wanita Tani dalam Usaha Produksi ABUCA (Abon dan Bubuk Cabai) di Kecamatan Adiluwih Kabupaten Pringsewu. Jurnal Sakai Sambayan 4 (2): 105-109.

Oscario A. 2013. Pentingnya Peran Logo Dalam Membangun Brand. Humaniora 4(1): 191-202

Pangaribuan L. 2016. Pemanfaatan Masker Bunga Rosella untuk Pencerahan Kulit Wajah. Jurnal keluarga Sehat Sejahtera 14 (28): 46-58 